Respect as an engine for new ideas: Linking respectful engagement, relational information processing and creativity among employees and teams human relations 2015, Vol. 68(6) 102I-1047 (C) The Author(s) 2015

Reprints and permissions: sagepub.co.uk/journalsPermissions.nav DOI: I0.1 I77/00|87267|4550256 hum.sagepub.com

\title{
Abraham Carmeli
}

Tel Aviv University, Israel

\section{Jane E Dutton}

Ross School of Business, USA

\section{Ashley E Hardin}

Ross School of Business, USA

\begin{abstract}
In four studies we examine whether and why respectfully engaging with other organizational members can augment creativity for individuals and teams. We develop and test a model in which respectful engagement among organizational members facilitates relational information processing, which in turn results in enhanced creative behaviors. We found a similar pattern across all four studies - respectful engagement is indirectly related, through relational information processing, to creative behavior at both the individual and team levels. These findings underscore the importance of respectful engagement in facilitating relational information processing and fostering creative behaviors at both the individual and team levels.
\end{abstract}

\section{Keywords}

creativity, high quality work relationships, relational information processing, respect

\section{Corresponding author:}

Abraham Carmeli, Faculty of Management, Tel Aviv University, Ramat Aviv, Tel Aviv 69978, Israel.

Email: avic@post.tau.ac.il 
Organizations seek ways to augment their members' creativity because of its potential to contribute to their firm's competitive edge. A key challenge in augmenting creativity is the social context of the workplace in which the creativity unfolds (Amabile, 1983; Harrington, 1990; Simonton, 2000). Scholars have shown particular interest in how the social context augments or inhibits creativity (Liao et al., 2010; Perry-Smith, 2006). This research addresses how changing social contexts, rather than modifying creative personality structures, creates conditions that facilitate members' creativity (Khazanchi and Masterson, 2011).

Relationships are a key aspect of the social context influencing creativity. Social network theorists suggest that the structure of an individuals' network influences his or her capacity to generate ideas (Burt, 2004) across diverse domains (Uzzi and Spiro, 2005). Individuals with a large number of weak ties have access to a set of diverse knowledge that fuels new ideas (Granovetter, 1973; Perry-Smith and Shalley, 2003). In this sense, weak ties, as compared with strong ties (measured by interaction duration and frequency), are a source of non-redundant information that facilitates creativity (Perry-Smith, 2006). However, recent empirical research has documented that strong ties can also be key for facilitating idea generation (Sosa, 2011: 16). Thus, actors' idea networks must encompass a large number of ties, as well as close ties in his/her networks for creativity to be enhanced (Baer, 2010). Research linking ties to creativity tends to construe relationships as vehicles for social exchange (Blau, 1964), and emphasizes that relationships are important because they allow for the instrumental exchange of resources between individuals (e.g. Homans, 1974; Thibaut and Kelly, 1959).

In this article, we suggest that relationships more directly influence the creative process by enhancing individuals' capacities and motivating them to engage with others. In particular, if individuals interrelate in ways that foster respect, relationships serve as means for endogenously resourcing individuals and fostering creativity. This endogenous resourcing viewpoint complements a more exogenous resourcing approach, as captured in a social exchange perspective.

Specifically, we focus on the potency of respectful engagement (RE) as a key form of positive interrelating and examine its influence on creativity at the individual and team levels. Our interest in respect is derived from two assumptions. First, respect is a foundational condition of human connections, representing an affirmation of human existence and dignity (Rawls, 1971). Second, RE is not automatic, but depends on one person granting presence, dignity and affirmation to another (Mead, 1934). Thus, RE implies that respect takes place interpersonally through particular forms of interaction. This definition of respect focuses on interpersonal actions that confer a sense of value and worth. $\mathrm{RE}$ focuses on the behaviors that create respect, distinguishing it from mutual respect, an asset that marks a particular relationship or set of relationships in a team or organization (e.g. Gittell, 2003). Based on a review of the organizational literature, Dutton (2003) suggests that acts of RE include conveying presence, communicating affirmation, effective listening and supportive communication. When employees perceive each other acting in these ways it manifests higher levels of RE.

We suggest that greater levels of RE should foster creativity. Work on respectful interaction (Weick, 1993) and organizational respect (Ramarajan et al., 2008) focuses on how these relational variables prevent negative conditions for individuals and groups in organizations, with less attention towards beneficial activities (e.g. creativity). For example, respectful interaction has been studied in the context of high reliability and resilience, showing that it fosters early mistake detection and initiates early corrective actions (e.g. Vogus, 2011). Survey studies 


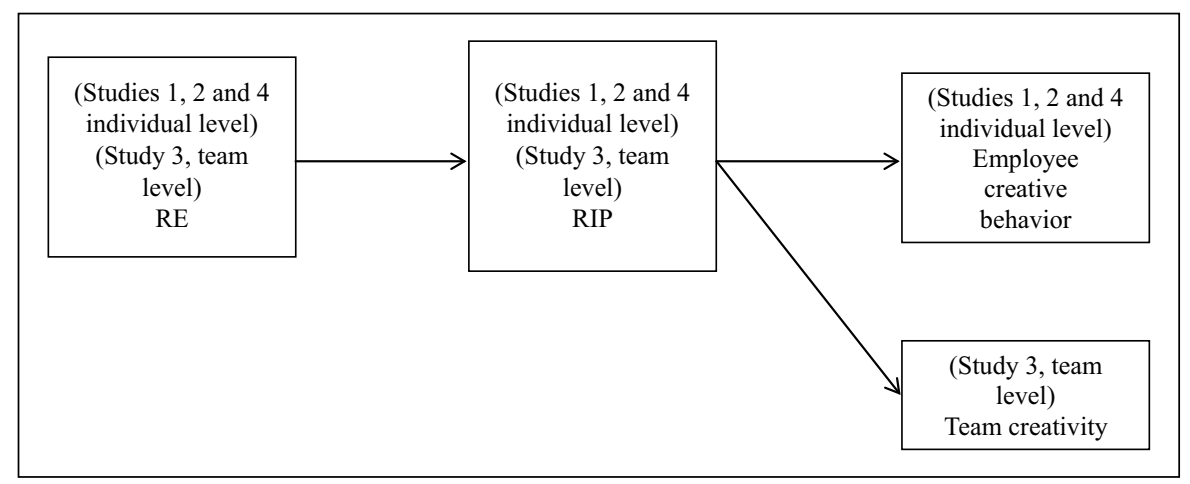

Figure I. Hypothesized relationships between variables in Studies I, 2, 3 and 4. Notes: RE = respectful engagement; RIP = relational information processing.

(e.g. Vogus, 2006) and case studies (e.g. Weick, 1993) suggest that respectful interaction, and the mindfulness that it creates, fosters the detection and correction of errors. Researchers show how conditions of organizational respect reduce emotional exhaustion for health care workers (Ramarajan et al., 2008). These studies suggest that respectful interaction, as a quality of organizational or collective groups, can prevent negative or undesirable conditions.

We propose and test a mediation model in which RE indirectly, through the facilitation of relational information processing (RIP), fosters creativity at both individual and team levels (see Figure 1). We theorize how this form of interrelating facilitates RIP, which serves as a key input to creative behaviors.

\section{Respectful engagement (RE)}

Respect captures the state of being seen (Honneth, 1992) and valued (Goffman, 1967). RE refers to interrelating that conveys a sense of presence and worth and communicates positive regard (Rogers, 1957). Although respect has received considerable attention in marital and relationship sciences (e.g. Gottman, 1994), less attention has been directed to respect at work. When respect has been considered in organizations, it is often viewed as either a manifestation of one's status (Blader and Tyler, 2009) or as a facet of relational quality (e.g. Carmeli and Gittell, 2003). We focus on behaviors that convey respect among members of an organization or team. Building on Dutton's (2003) definition, these behaviors include recognizing another person, understanding and appreciating them, listening, attending to needs, emphasizing another's good qualities, and making requests not demands (Rosenberg, 2003).

$\mathrm{RE}$ is a distinctive relational construct in organizational studies. First, RE is distinct from leader-member exchange (LMX) theory, which focuses on mutual respect as one aspect of the quality of leader-subordinate relationships (along with obligation and trust; Graen and Uhl-Bien, 1995). Second, RE focuses on members' actual behaviors in interactions with one another rather than resources these behaviors generate, making it different from coworker support (Chiaburu and Harrison, 2008), perceptions of interpersonal risks (e.g. psychological safety; Edmondson, 1999) or states of being in relationship with 
others such as a willingness to accept vulnerability (i.e. trust; Mayer et al., 1995). Further, $\mathrm{RE}$ is distinct from perceived organizational support (POS), which focuses on beliefs about the organization's support for members, rather than on how members treat and interrelate with each other (Rhoades and Eisenberger, 2002). RE also highlights a particular set of behavioral interactions, whereas social cohesion captures the forces that operate on an individual to retain them as a group member (Festinger, 1950; Friedkin, 2004). RE also differs from collaboration, which captures helping in workload management and creating flexibility that aids task completion (Hambrick, 1994). Finally, we distinguish between RE and a negative relationship condition, task conflict (defined as 'disagreements among team members about the content of the tasks being performed' [Jehn, 1995: 258]), which allowed us to test for potential positivity bias in participants' responses (Study 4).

While much research construes relationships as the basis of resource exchange (e.g. POS, LMX, trust, collaboration), RE highlights that interrelating at work can be based on less instrumental and more humanizing forms of interpersonal connection, emphasizing the importance of being accepted as a person of worth and value. This perspective highlights that interactions can be a mutually developmental experience through which people grow and adapt to each other, rather being a conduit for the exchange of resources (Stephens et al., 2012). RE is an important relational mechanism through which individuals are accepted as a person of worth (Dutton et al., forthcoming), feelings that are not guaranteed at work (e.g. studies on dirty work, interpersonal sensemaking and abusive treatment at work; Ashforth and Kriener, 1999; Dutton et al., forthcoming; Tepper, 2007).

The power of RE is evident in how it fosters acceptance and openness, motivates interaction and equips individuals for engaging with one another. First, when members respectfully engage one another, they send a message of positive regard, a 'warm, acceptant attitude' toward other people (Rogers, 1967: 94). This sense of acceptance opens people up to diverse points of view and makes them more attentive when engaging with people who might be different from themselves (Dutton, 2003; Tjosvold et al., 1981). The sense of being accepted arises when others convey genuine interest through RE.

Second, when people engage respectfully there is an enhanced motivation to be with and contribute to one another. RE motivates interaction because it satisfies conditions for human growth and development: the need to belong (e.g. Baumeister and Leary, 1995) as well as acceptance and love (Fredrickson, 2013). RE also encourages mutual empowerment, associated with openness and zest, allowing people to grow-in-relationship (Miller and Stiver, 1997). Through RE, individuals can authentically connect to themselves and others in ways that allow for greater mutual awareness, acceptance and responsiveness owing to a psychological presence (Kahn, 1992) cultivated through genuine interaction (Rogers, 1967). This way of interrelating enables individuals and teams to be more resilient and able to make real-time adjustments (Stephens et al., 2013). Thus, RE motivates immediate and future interpersonal attention to and interest in other people.

At the same time, if organizational members are engaging with one another respectfully, the sense of being interpersonally accepted, valued and affirmed will call up positive emotions like appreciation and gratitude (respect, appreciation and gratitude often cluster together; Strom and Storm, 1987). These positive interpersonal emotions broaden people's capacities to build other forms of durable resources such as the capacity to adapt. Positive emotions strengthen people from within and equip them to be more 
resourceful and resilient (Fredrickson, 1998). We propose that when individuals experience this, they are more willing and capable of creating reflective conversations about their work and work goals. Together these arguments form the bases for theorizing that RE motivates and builds capacity to engage in RIP.

\section{Perceived organizational support and relational information processing}

RIP is the process through which organizational members use conversation, a basic unit of human interaction essential for organizational communication (Ford and Ford, 1995), to reflect upon their goals and work. Reflection is a key practice in which people think about what has been done, why and how. Research has shown that reflecting on one's experience produces more effective learning and enhanced performance (Di Stefano et al., 2014). This type of reflection can be done in isolation or in conversation with others. RIP falls into the latter type of information processing, which involves reflection-inconversation - a process wherein people engaging in ongoing attempts to reflect on work tasks and practices with colleagues. RIP captures the degree to which organizational members actively engage each other about their goals and ways of doing their work.

RIP not only differs from existing research in its focus on reflection-in-conversation rather than self-reflection; it also differs from the construct of social information processing, which points to how individuals rely on their immediate social contexts for salient cues that inform their attitudes and behaviors (Salanick and Pfeffer, 1978). While both social and RIP emphasize members' immersion in a social context, RIP captures a more active level of interpersonal behavior, seeking colleagues' inputs and reactions to their work conduct. In this sense, RIP involves thinking deeply with others resulting in more extensive real-time search and exploration, compared with a less effortful means of information processing of using heuristics or relying on past experiences (Chaiken and Trope, 1999; De Dreu, 2007).

We argue that members who engage in RE are more motivated and equipped to engage in RIP. We suggest that RE motivates and strengthens individuals so that they have a greater desire and capacity for seeking and processing information about what they do and aspire to do at work. This is because recognizing, accepting and affirming other persons and what they have to offer fosters conversations where people can constructively think about what they do at work, why and how. In other words, RE among colleagues signals acceptance, genuine mutual interest in other persons and their thoughts and reactions, such that a greater capacity for deeper and more nuanced information processing about work is developed. This logic leads to our first hypothesis:

Hypothesis 1: RE is positively related to RIP.

\section{Relational information processing and creativity}

We suggest that RIP will positively influence creativity at both the individual and group levels. Individual creativity is the production of ideas, products or procedures that are 
novel and potentially useful to the organization (Amabile, 1983). However, group creativity is a shared activity (Paulus, 2008) defined as 'the production of novel and useful ideas concerning products, services, processes, and procedures by a team of employees' (Shin and Zhou, 2007: 1715).

All organizational members possess unique attention and information that they can apply to ideation (Nijstad and Paulus, 2003). However, to comprehend the world and understand patterns, people need to process this information (i.e. developing knowledge; Nonaka, 1994). We propose that when colleagues engage in greater levels of RIP, they are likely to produce more original and useful ideas for two reasons: 1) they are more likely to build upon others' thoughts and integrate these different perspectives; and 2) they are more likely to have original and useful ideas.

First, when individuals discuss tasks and practices with colleagues, they are more likely to generate, build on and combine a greater variety of information. Accessing and building on others' unique perspectives and expertise contributes to the combination of unique information, which leads to developing new solutions (Hargadon, 2008). In addition, we suggest that RIP is likely to lead people to develop openness and receptivity to others' opinions (Mueller and Kamdar, 2011). Thus, through higher levels of RIP, members can utilize each other's unique expertise, cultivating new thinking pathways and generating new ideas.

Second, RIP develops mindfulness, an enriched awareness of a particular situation or issue (Rochlin, 1989: 164). When members engage in RIP, they are likely to discuss and reflect with each other, gaining a deeper understanding of the world. Through RIP, individuals interact in an open and nonjudgmental manner, which is associated with mindfulness (Bishop et al., 2004). By acting mindfully, people are engaged in the present (Langer and Moldoveanu, 2000), actively noticing and attending to what happens in an environment such that novel distinctions can be made, resulting in increased levels of creativity (Grant et al., 2004; West, 1996).

Thus, we theorize that RIP exposes members to more ideas, and makes them more attentive to shared ideas (Paulus and Coskun, 2012) such that it alters an individual's mindset enabling new lines of sight and encouraging further exploration. Greater reflection through conversation encourages the consideration of more unique ideas (De Dreu, 2007) and facilitates the combination of different perspectives for novel solutions (Hargadon, 2008; Kohn et al., 2011). Existing research supports this logic: those discussing counterfactual thoughts generate a wider variety of ideas (Paulus, 2000; Rietzschel et al., 2009) and those capitalizing on more diverse cognitive repertories generate more original and useful ideas (Paulus and Coskun, 2012). These arguments lead us to hypothesize that RIP facilitates the ideation process and promotes creativity at the individual and team levels:

Hypothesis 2a: RIP is positively associated with employees' creative behaviors. Hypothesis $2 b$ : RIP is positively associated with creativity in teams.

\section{The mediating role of RIP}

In combination, our hypotheses suggest a mediation model where RE facilitates RIP, which fosters creative behaviors. When people interrelate through RE, they send a clear message of acceptance and genuine interest. With this sense, people are more likely to 
open up and create a mutual process of inviting inputs and providing reactions, creating an enriched conversation about what, why and how things are done at work.

When members engage respectfully, they create and shape a more inviting work environment where people are encouraged to share their experiences. Members then draw on each other's experiences and expertise in enriching conversations (Lewis and Herndon, 2011). Through this sharing, members become knowledge wellsprings for each other, enabling the generation of more creative ideas (Paulus and Coskun, 2012).

Thus, our theorizing suggests that by engaging respectfully, people develop a sense of mutuality, which helps to cultivate psychological resources (Miller and Stiver, 1997) conducive for the development of both the motivation and capacity to engage in more reflection-in-conversation. This, in turn, fosters creative behaviors by both facilitating a process where people draw and build on others' unique inputs and cultivating mindfulness that allows an enriched awareness of context:

Hypothesis 3a: RIP will mediate the link between RE and employees' creative behaviors.

Hypothesis 3b: RIP will mediate the link between RE and creativity in teams.

\section{Method}

To test our hypotheses, we established our measure of RE and then conducted four additional studies to explicitly test our model. First, we developed a scale for RE and began to establish convergent and discriminant validity (further established in subsequent studies). Study 1 is a time-lagged survey of part-time undergraduate students. Study 2 replicates Study 1 in an organizational setting requiring creative solutions. Study 3 focuses on top management teams (TMTs), replicating the interdependence often involved in creative solutions. Finally, Study 4 replicates our findings in a different national context (USA).

\section{Respectful engagement measurement development, method}

We seek to establish both convergent and discriminant validity of RE by empirically examining the pattern of correlations between RE and related constructs (Campbell et al., 1996; DeVellis, 2003).

\section{Respectful engagement: Item development and validation}

Based on Dutton's (2003) conceptualization, we constructed a 14-item scale to assess the extent to which organizational members interact through RE. First, we asked 25 graduate students to assess if the items reflect the definition of RE. This resulted in few minor revisions to item wording, thus providing evidence of content validity.

Next, we conducted a pilot study of 120 senior undergraduate students (average age of 23 years, $40 \%$ female), 56 reported part-time employment. Participants received extra 
credit for participation, not contingent on completion. We asked respondents to assess on a five-point scale ( $1=$ not at all, to $5=$ to a very large extent) whether RE is the way organizational members interrelate at work.

\section{Respectful engagement measurement development, results}

In a conservative test, we factor analyzed the 14 items of RE, performing several factor analyses. We removed items that did not pass the cutoff value (.40) or had cross-loadings with other items $(>.25)$, resulting in a one-factor solution comprised of nine items $(\alpha=.93$; see Table 1). In the pilot study, we also examined whether RE was empirically distinct from a climate of psychological safety (e.g. It is difficult to ask other members of this organization for help; Edmondson, 1999). A factor analysis yielded a two-factor structure and a correlation of $28(p<.01)$ in support of our assumed distinctiveness of these two concepts.

Throughout our subsequent studies, we continue to establish the predictive validity of RE. We explore the relative explanatory power of RE on RIP over and above related relational constructs - LMX (Study 1), trust (Studies 2 and 3), collaboration (Study 3), POS, cohesion, psychological safety and task conflict (Study 4). Through these studies, we seek to sequentially and cumulatively rule out rival mechanisms that might influence RIP. Specifically, we assessed both discriminant and incremental validity by examining whether RE is correlated with measures of other constructs and whether RE added value in explaining variance in the outcome variable (Campbell and Fiske, 1959).

\section{Study I}

\section{Sample and procedure}

For the first test of our hypotheses, we collected survey data from part-time senior undergraduate students studying business at a large university. We used online survey software to collect data at three points in time with a lag of 10 days (time 1: independent and control variables; time 2: mediator; and time 3: dependent variable). Students received credit for participating in the university's behavioral lab, where we obtained a list of 230 students. Each student received an email with a survey link and a reminder email after four days. We received 212 usable surveys, fully completed at each time point $(92 \%$ response rate; $48 \%$ female; average age 23 years; average tenure two years). The use of time-lagged data reduces potential response biases associated with cross-sectional studies (Podsakoff et al., 2012).

\section{Measures}

Responses were reported on a five-point scale $(1=$ not at all, to $5=$ to a very large extent $)$.

Creativity. To assess creativity, we used a four-item scale employed by Baer and Oldham (2006) (e.g. Often comes up with creative solutions to problems at work, and suggests 
Table I. Study I, factor analysis results for respectful engagement and relational information processing.

$R E$

Organizational members here are always available to hear out and listen to

each other

Organizational members here pay the utmost attention to each other's needs

Organizational members here express genuine interest in each other's

position and the units they are managing and responsible for

Organizational members here recognize and understand what goes into each

other's work

Organizational members here emphasize other members' good sides

Organizational members here express appreciation and respect for each

other's contribution to the organization

Organizational members here appreciate how valuable other members' time is

Organizational members here speak to each other in a respectful rather than

in a demanding way

RIP

I thoroughly reflect upon my goals and the ways to attain them with my colleagues at work

I thoroughly reflect upon the way things are done with my colleagues at work

I constantly discuss questions with my colleagues at work about why am I using certain ways of doing things and whether there are better alternatives to complete the tasks

Eigenvalues

$\%$ of variance explained

many creative ideas that might improve working conditions at work; adapted from Zhou and George, 2001). To mitigate potential response bias, we asked respondents to assess the extent to which their managers think they display creativity. The results of factor analysis produced a one-factor solution with an eigenvalue of 3.10 and an explained variance of 77.54 percent $(\alpha=.90)$.

RIP. We used three items to assess the extent to which respondents engage in deep information processing with their colleagues at work (e.g. I thoroughly reflect upon my goals and the ways to attain them with my colleagues at work, and I constantly discuss with my colleagues at work questions about why I am using certain ways of doing things and whether there are better alternatives to complete the tasks; De Dreu, 2007; Van Kleef et al., 2004). As noted below, we factor analyzed the items together with RE and the results showed that this measure was distinct from $\operatorname{RE}(\alpha=.71)$.

RE. We assessed RE using the nine-item scale we developed $(\alpha=.85)$. 
Table 2. Study I, means, standard deviations (SD) and correlations.

\begin{tabular}{|c|c|c|c|c|c|c|c|c|}
\hline & Mean & SD & I & 2 & 3 & 4 & 5 & 6 \\
\hline I. Gender (I = Female) & - & - & 1.00 & & & & & \\
\hline 2. Age & 23.42 & 2.50 & $-.33^{* *}$ & 1.00 & & & & \\
\hline 3. Tenure in the organization & 1.92 & 1.67 & -.12 & $.25^{* *}$ & 1.00 & & & \\
\hline 4. RE & 3.34 & 0.58 & .05 & .08 & -.01 & 1.00 & & \\
\hline 5. RIP & 3.65 & 0.66 & $.14^{*}$ & .01 & .10 & $.32^{* *}$ & 1.00 & \\
\hline 6. Creative behaviors & 3.61 & 0.75 & -.08 & .02 & $.16^{*}$ & $.29^{* *}$ & $.30^{* *}$ & 1.00 \\
\hline
\end{tabular}

Listwise $N=212$ Two-tailed test. SD = standard deviation. ${ }^{*} p<.05,{ }^{* *} p<.01$.

Controls. We controlled for several potential influences on creativity including: 1) gender differences; 2) organizational tenure; 3 ) education; and 4) respondent age.

\section{Study I, results}

\section{Construct validity}

We first examined the correlation between RE and LMX, using a 12-item LMX-MDM scale (Liden and Maslyn, 1998). Results indicate a correlation of $.32(p<.01)$. We separately assessed the power of RE beyond LMX, with LMX entered in the first block and $\mathrm{RE}$ entered in the second block. Results indicate that RE explained an additional 6.6 percent of the variance in RIP above $\operatorname{LMX}(F$ Change $=15.83, p<.01)$.

\section{Hypotheses testing}

We conducted a confirmatory factor analysis (CFA) to test the discriminant validity of RE, RIP and creativity. We compared a three-factor model with a two-factor model (collapsing RE and RIP) and a one-factor model (collapsing all three). Results indicate that a three-factor model showed an acceptable fit with the data ( $\chi^{2}$ [d.f.] $=246.7$ $[101]$, Incremental Fit Index $[\mathrm{IFI}]=.90$, Tucker Lewis Index $[\mathrm{TLI}]=.86$, Comparative Fit Index $[\mathrm{CFI}]=.90$ and Root Mean Square Error of Approximation [RMSEA] = $.08)$, compared with either the two-factor model $\left(\chi^{2}\right.$ [d.f.] $=348.1$ [103], IFI $=.83$, TLI $=.77, \mathrm{CFI}=.82$ and $\mathrm{RMSEA}=.11)$, or the one-factor model $\left(\chi^{2}[\mathrm{~d} . \mathrm{f}\right.$.] $=786.3$ [104], $\mathrm{IFI}=.52, \mathrm{TLI}=.36, \mathrm{CFI}=.51$ and $\mathrm{RMSEA}=.18)$, thus establishing the discriminant validity of the research variables. This suggests that response biases are not likely to be severe.

Table 2 displays the descriptive statistics. To test the research hypotheses, we conducted a series of hierarchical regression analyses. Each regression equation entered the control variables in the first step. The results in Model 2 in Table 3 indicate that Hypothesis 1, which posited a positive relationship between RE and RIP, was supported $(\beta=.31, p<.01)$. 
Table 3. Study I, hierarchical regression results for the prediction of relational information processing (RIP) and employee creative behaviors.

\begin{tabular}{|c|c|c|c|c|}
\hline & Model I $\beta$ & Model $2 \beta$ & Model $3 \beta$ & Model $4 \beta$ \\
\hline & $\begin{array}{l}\text { Employee creative } \\
\text { behaviors }\end{array}$ & RIP & $\begin{array}{l}\text { Employee creative } \\
\text { behaviors }\end{array}$ & $\begin{array}{l}\text { Employee creative } \\
\text { behaviors }\end{array}$ \\
\hline Constant $^{(I)}$ & $2.78\left(4.97^{* *}\right)$ & $2.25\left(4.60^{* *}\right)$ & $2.82\left(4.98^{* *}\right)$ & $2.17(3.79 * *)$ \\
\hline Gender ( $($ = female) & $-.09(-1.40)$ & $.15(2.11 *)$ & $-.13\left(-1.93^{*}\right)$ & $-.13\left(-1.93^{*}\right)$ \\
\hline Age & $-.08(-1.14)$ & $.00(.05)$ & $-.07(-.95)$ & $-.08(-1.18)$ \\
\hline $\begin{array}{l}\text { Tenure in the } \\
\text { organization }\end{array}$ & $.17\left(2.57^{*}\right)$ & $.12(1.78)$ & $.13(1.93)$ & $.13(2.19)$ \\
\hline$R^{2}$ & .03 & .036 & .032 & .031 \\
\hline Adjusted $R^{2}$ & .17 & .022 & .018 & .017 \\
\hline$F$ for $R^{2}$ & 2.20 & 2.58 & 2.32 & 2.20 \\
\hline SE of the estimate & .747 & .654 & .750 & .745 \\
\hline RIP & & & $.30\left(4.53^{* *}\right)$ & $.24(3.49 * *)$ \\
\hline$\Delta R^{2}$ & & & .087 & .093 \\
\hline$F$ for $\Delta R^{2}$ & & & $20.55^{* *}$ & $21.89 * *$ \\
\hline$R^{2}$ & & & .119 & .124 \\
\hline Adjusted $R^{2}$ & & & .102 & .107 \\
\hline SE of the estimate & & & .717 & .717 \\
\hline$R E$ & $.30(4.60 * *)$ & .31 (4.77**) & & $.23(3.39 * *)$ \\
\hline$\Delta R^{2}$ & .121 & .095 & & .046 \\
\hline$F$ for $\Delta R^{2}$ & $21.20 * *$ & $22.7 \mid * *$ & & II.49** \\
\hline$R^{2}$ & .121 & .131 & & .17 \\
\hline Adjusted $R^{2}$ & .104 & .114 & & .15 \\
\hline SE of the estimate & .713 & .622 & & .694 \\
\hline
\end{tabular}

(I)Unstandardized coefficients; ${ }^{*} p<.05,{ }^{* *} p<.01$.

We also tested whether RIP was positively related to creative behaviors (Hypothesis 2), and whether RIP mediated the relationship between RE and creative behavior (Hypothesis 3). To test for mediation we used a bootstrap method (Preacher and Hayes, 2004). A bootstrap analysis using 10,000 iterations with 95 percent confidence interval (CI) (bias-corrected confidence interval excludes zero) indicated that the indirect effect through RIP as mediator is significant $(95 \% \mathrm{CI}=.098$ [lower], .446 [upper]; $p=.003)$, thus supporting a mediation model.

\section{Study 2, method}

Although a study of part-time students provides important insights, it may differ from a study of employees who work full time and engage in their workplace more intensely. Study 2 examines our research model in a service organization of technicians who aim to solve customer problems that may require creative solutions. Study 2 replicates and extends Study 1's results. 


\section{Sample and procedure}

We surveyed 150 full-time technicians at both the system and delivery levels, working in a utility service organization. A senior manager provided access to administer the survey on site. A cover letter described the study's goals and assured participants confidentiality.

We received 116 completed surveys for a response rate of 77.33 percent. The respondents' average age was 45 years (standard deviation [SD] 7), and their average tenure in the organization was 20 years (SD 7). Females were 3 percent, 44.5 percent had a high-school diploma, 36.8 percent had a BA degree, and the remainder had a MA degree. We found no statistically significant differences between respondents and non-respondents $(p>.10)$.

Measures. Responses were reported on a five-point scale $(1=$ not at all, to $5=$ to a very large extent).

Creative behaviors. We used the same four-item scale to assess creative behaviors (Baer and Oldham, 2006) $(\alpha=.93)$. We compared creative behaviors with results from a creativity task that was administered after the participants had completed the survey. The results indicate a positive relationship between creative behaviors and both fluency $(p<$ $.05)$ and originality $(p<.01)$.

RIP. We used the same items as in Study 1 to assess RIP. The factor analysis produced a one-factor solution with an eigenvalue of 1.94 and an explained variance of 64.54 percent $(\alpha=.73)$.

RE. We employed the same nine-item scale to assess RE.

Controls. As in Study 1, we controlled for gender differences, age, tenure in the organization and education.

\section{Study 2, results}

\section{Construct validity}

Study 2 assesses the construct validity of RE in relation to LMX and trust. To measure trust, we adapted an existing six-item scale to assess its presence in relationships between the participants and their colleagues (e.g. members relate to each other with high sincerity and, in general, members' motives and intentions are good; $\alpha=.88$; Robinson, 1996). We performed factor analysis on items measuring both trust and RE to examine their empirical distinctiveness. Results produced a two-factor solution. The first factor consisted of nine items measuring RE had an eigenvalue of 5.49 and an explained variance of 36.62 percent. The second factor consisted of six items measuring trust, had an eigenvalue of 4.11 and an explained variance of 27.37 percent. No items had cross-loadings of greater than .30 $(\alpha=.92)$. We then assessed the relative influence of RE beyond LMX and trust, with LMX and trust entered in the first block and RE entered in the second block. Results indicated that RE explained an 
Table 4. Study 2, means, SD and correlations.

\begin{tabular}{lllllllllll}
\hline & Mean & SD & I & 2 & 3 & 4 & 5 & 6 & 7 & 8 \\
\hline Gender (I = female) & - & - & 1.00 & & & & & & & \\
Age & 44.86 & 7.25 & -.02 & 1.00 & & & & & & \\
Tenure in the & 20.24 & 6.62 & -.08 & $.85^{* *}$ & 1.00 & & & & & \\
organization & & & & & & & & & & \\
Education & 2.87 & 2.00 & -.15 & -.02 & -.03 & 1.00 & & & & \\
Trust & 3.90 & .68 & -.03 & $.18^{*}$ & .14 & -.02 & 1.00 & & & \\
RE & 3.34 & .70 & .04 & .14 & .15 & -.10 & $.57^{* *}$ & 1.00 & & \\
RIP & 3.50 & .91 & -.01 & .11 & .08 & -.02 & $.48^{* *}$ & $.52^{* *}$ & 1.00 & \\
Creative behaviors & 3.99 & .85 & -.13 & $.19^{*}$ & .14 & .12 & $.33^{* *}$ & $.34^{* *}$ & $.43^{* *}$ & 1.00 \\
\hline
\end{tabular}

Listwise $N=116$ Two-tailed test. SD = standard deviation; $R E$ = respectful engagement; $R I P=$ relational information processing.

${ }^{*} p<.05,{ }^{* *} p<.01$.

additional 2.5 percent of the variance in RIP above both LMX and trust $(F$ Change $=$ $5.44, p<.05)$.

\section{Hypotheses testing}

We performed a CFA to establish the discriminant validity of RE, RIP and creative behaviors. We compared a three-factor with a two-factor model (collapsing RE and RIP) and a onefactor model (collapsing all three). Results indicated that a three-factor model showed an acceptable fit with the data $\left(\chi^{2}\right.$ [d.f.] $=204.7$ [101], incremental fit indices [IFI] $=.92$, Tucker Lewis Index $[\mathrm{TLI}]=.91$, comparative fit index $[\mathrm{CFI}]=.92$ and Root Mean Square Error of Approximation $[$ RMSEA] $=.08)$, compared with either a two-factor model $\left(\chi^{2}[\right.$ d.f. $]=279.6$ [103], IFI $=.87, \mathrm{TLI}=.85, \mathrm{CFI}=.87$ and $\mathrm{RMSEA}=.12)$, or a one-factor model $\left(\chi^{2}\right.$ [d.f.] $=$ $665.6[104], \mathrm{IFI}=.59, \mathrm{TLI}=.52, \mathrm{CFI}=.58$ and $\mathrm{RMSEA}=.21)$, thus establishing the discriminant validity of the research variables. This also suggests that potential response biases are not likely to be severe. We estimated the effect of a theoretically unrelated marker variable that may be expected to explain shared variance attributable to the common method variance (CMV) (Williams and Anderson, 1994). For the marker variable, we used three items to measure supportive leadership, a sub-scale of transformational leadership (e.g. considers my personal feelings before acting and behaves in a manner that is thoughtful of my personal needs; Rafferty and Griffin, 2004). The CMV among RE, RIP and creative behaviors was expected to be effectively captured by this marker because it should share any common relational factors with these variables that are conducive to creative behaviors. We then estimated the effect of the supportive leadership marker variable on all observed variables, but we did not allow it to correlate with any other latent variables (Williams and Anderson, 1994). This model did not fit the data well $\left(\chi^{2}[\mathrm{~d} . \mathrm{f}\right.$.] $=403.9$ [134], CFI $=.86, \mathrm{IFI}=.86, \mathrm{TLI}=.80$ and RMSEA $=.10$ ) suggesting that the possibility of a common method effect is rather low.

Table 4 shows the study's descriptive statistics for the variables. To test our hypotheses, we performed hierarchical regression analyses with each equation entering the control variables, including trust, in the first step. We examined Hypothesis 1, which posited a positive relationship between RE and RIP. The results of model 2 in Table 5 support this hypothesis $(\beta=.36, p<.01)$. 
Table 5. Study 2, hierarchical regression results for the prediction of RIP and employee creative behaviors.

\begin{tabular}{|c|c|c|c|c|}
\hline & Model I $\beta$ & Model $2 \beta$ & Model $3 \beta$ & Model $4 \beta$ \\
\hline & $\begin{array}{l}\text { Employee } \\
\text { creative } \\
\text { behaviors }\end{array}$ & RIP & $\begin{array}{l}\text { Employee } \\
\text { creative } \\
\text { behaviors }\end{array}$ & $\begin{array}{l}\text { Employee } \\
\text { creative } \\
\text { behaviors }\end{array}$ \\
\hline Constant $^{(I)}$ & I.79 (2.39*) & I.84 $\left(2.46^{*}\right)$ & $2.04\left(2.72^{* *}\right)$ & $2.04\left(2.72^{* *}\right)$ \\
\hline Gender $(I=$ female $)$ & $-.11(-1.34)$ & $-.02(-.20)$ & $-.10(-1.26)$ & $-.11(-1.32)$ \\
\hline Age & $.27(\mathrm{I} .8 \mathrm{I})$ & $-.01(-.05)$ & $.27(1.86)$ & $.28(1.90)$ \\
\hline $\begin{array}{l}\text { Tenure in the } \\
\text { organization }\end{array}$ & $-.15(-.99)$ & $.01(.09)$ & $-.15(-1.00)$ & $-.15(-1.06)$ \\
\hline Education & $.14(1.61)$ & $.02(.29)$ & $.12(1.50)$ & .13 (1.59) \\
\hline Trust & $.13(1.21)$ & $.29\left(3.16^{* * *}\right)$ & $.08(.90)$ & $.03(.3 \mathrm{I})$ \\
\hline$R^{2}$ & .139 & .262 & .139 & .139 \\
\hline Adjusted $R^{2}$ & .104 & .232 & .104 & .104 \\
\hline$F$ for $R^{2}$ & $3.96^{* *}$ & $8.75^{* *}$ & $3.96^{* *}$ & $3.96^{* *}$ \\
\hline SE of the estimate & .791 & .784 & .750 & .791 \\
\hline$R I P$ & & & $.36\left(3.84^{* *}\right)$ & $.32\left(3.27^{* *}\right)$ \\
\hline$\Delta R^{2}$ & & & .093 & .093 \\
\hline$F$ for $\Delta R^{2}$ & & & $14.74^{* *}$ & $14.74^{* * *}$ \\
\hline$R^{2}$ & & & .232 & .232 \\
\hline Adjusted $R^{2}$ & & & .194 & .194 \\
\hline SE of the estimate & & & .750 & .750 \\
\hline$R E$ & $.23\left(2.20^{*}\right)$ & $.36\left(3.85^{* *}\right)$ & & .II (I.08) \\
\hline$\Delta R^{2}$ & -.033 & .08 & & .007 \\
\hline$F$ for $\Delta R^{2}$ & $4.82^{*}$ & $14.84^{* *}$ & & 1.16 \\
\hline$R^{2}$ & .171 & .342 & & .239 \\
\hline Adjusted $R^{2}$ & .131 & .310 & & .195 \\
\hline SE of the estimate & .779 & .743 & & .749 \\
\hline
\end{tabular}

(I)Unstandardized coefficients; ${ }^{*} p<.05,{ }^{* *} p<.0 \mathrm{I} . \mathrm{SE}=$ standard error; RIP = relational information processing; $\mathrm{RE}=$ respectful engagement.

We also tested whether RIP was positively related to creative behaviors (Hypothesis 2), and whether RIP mediated the relationship between RE and creative behavior (Hypothesis 3). As in Study 1, we performed bootstrap analysis (Preacher and Hayes, 2004), the results indicated that the indirect effect through RIP as mediator is significant $(95 \% \mathrm{CI}=.126$ [lower], .516 [upper]; $p=.03)$, thus supporting a mediation model.

We also assessed an individual's level of divergent thinking having them complete Guilford's alternative uses task (1967), where participants listed as many uses for a brick as possible. Two independent coders assessed their responses for fluency (number of ideas) and originality (number of highly original solutions below 1\%). This divergent thinking test assesses, at best, one's creative potential (see Sternberg and Lubart, 1996). We found that the correlations between self-reported creativity and these creativity tests were $.22(p<.05)$ and $.33(p<.01)$, respectively, providing further assurance about our self-reported creativity measure. We also used three items 
from the trust scale (Robinson, 1996) as the marker latent variable. The trust marker latent variable on all observed variables was estimated, but we did not allow it to correlate with any other latent variables. This model exhibited a poor fit with the data $\left(\chi^{2}\right.$ [d.f.] $=332.2[147], \mathrm{CFI}=.90, \mathrm{IFI}=.90, \mathrm{TLI}=.88$ and $\mathrm{RMSEA}=.10)$ suggesting that a common method effect is less likely to be critical. These analyses suggest that we cannot entirely rule out some shared CMV, but the latter did not have a substantial influence on the hypothesized effects.

\section{Study 3, method}

In Study 3, we examine our hypotheses in work teams. We specifically focus on top management teams (TMTs) because members work interdependently, often needing to process a variety of information to come up with creative solutions for ill-defined problems.

\section{Sample and procedure}

As part of a larger project, we accessed TMTs from 500 firms (see Carmeli et al., 2011, 2012). ${ }^{1} 82$ TMTs (82 CEOs and 230 of their TMT members; response rate of $16.4 \%$ ) provided usable data (defined as teams with at least $50 \%$ of the members completed the questionnaires; see Lubatkin et al., 2006). Sample firms operated in diverse industries. Participating and non-participating firms were not statistically significantly $(p>.10)$ different in terms of size as measured by the number of employees.

Measures. Responses were reported on a five-point scale $(1=$ not at all, to $5=$ to a very large extent).

Team creativity. We adapted Lubatkin et al.'s (2006) four-item scale that assesses team exploration orientations: search, discovery, experimentation and risk-taking. The CEO assessed the extent to which each team was creative (e.g. looks for novel technological ideas by thinking outside the box and looks for creative ways to satisfy its customers' needs; $\alpha=.81)^{2}$

Team RIP. We used the same three items to assess the extent individuals reflect together on their goals and ways to attain them, modifying items to capture team-level dynamics (e.g. De Dreu, 2007; Van Kleef et al., 2004). Sample items include: team members engage in an in-depth discussion about the desired ends and the ways to attain them and team members reflect upon the ways things are done. Factor analysis produced a onefactor solution with an eigenvalue of 2.44, explained 81.31 percent of variance, with all item-loadings above .76. Aggregation test values adhere to conventional standards for aggregating individual responses to the team level (see Bliese, 2000; intraclass correlations $\left.[\mathrm{ICC}][1]=.60 ; \mathrm{ICC}[2]=.88 ; \mathrm{R}_{\mathrm{wg}}=.90 ; \alpha=.88\right)$.

Team RE. Similarly, we employed the same nine items to assess RE, modifying items to apply at the team level. Sample items include: team members here appreciate how valuable their team members' time is and team members here speak to each other in a 
Table 6. Study 3, means, SD and correlations.

\begin{tabular}{|c|c|c|c|c|c|c|c|c|c|c|}
\hline & Mean & SD & I & 2 & 3 & 4 & 5 & 6 & 7 & 8 \\
\hline I. Sector $(I=$ Service $)$ & - & - & 1.00 & & & & & & & \\
\hline 2. Team size & 5.12 & 1.03 & -.14 & 1.00 & & & & & & \\
\hline 3. Team tenure & 8.79 & 5.51 & $.25^{*}$ & .08 & 1.00 & & & & & \\
\hline 4. Education & 4.35 & .58 & .09 & .08 & -.02 & 1.00 & & & & \\
\hline $\begin{array}{l}\text { 5. Perceived environmental } \\
\text { uncertainty }\end{array}$ & 2.62 & .58 & .14 & -.03 & $-.23^{*}$ & -.06 & 1.00 & & & \\
\hline 6. Team RE & 3.55 & .50 & .10 & -.11 & -.09 & .09 & .08 & 1.00 & & \\
\hline $\begin{array}{l}\text { 7. Team information } \\
\text { processing }\end{array}$ & 3.54 & .58 & .00 & .21 & .10 & -.11 & .14 & $.27^{*}$ & 1.00 & \\
\hline 8. Team creativity & 3.85 & .45 & -.06 & .00 & -.08 & -.10 & .14 & $.33^{*}$ & $.46^{* *}$ & 1.00 \\
\hline
\end{tabular}

$N=82$ Two-tailed test. $\mathrm{SD}=$ standard deviation; $\mathrm{RE}=$ respectful engagement. ${ }^{*} p<.05,{ }^{* *} p<.01$.

respectful and not a demanding way. Factor analysis produced a one-factor solution with an eigenvalue of 5.88, explained 65.38 percent of variance, with item-loadings above .77. Aggregation test values were $\operatorname{ICC}(1), \operatorname{ICC}(2)$ and $\mathrm{R}_{\mathrm{wg}} .57, .92$ and 91 , respectively $(\alpha=.93)$.

Controls. Owing to potential effects on creative behavior, we controlled for potential sector and industry differences (service versus industrial), team size (O'Reilly and Flatt, 1989), team education level (Amabile, 1988), team tenure and perceived environmental uncertainty (e.g. often our firm is required to change its operations because of customers' changing needs and the life cycle of products/services in the industry is short; $\alpha=.79$; Miller and Droge, 1986).

\section{Study 3, results}

\section{Construct validity}

In Study 3, we first examined the correlation between collaboration and RE and found a correlation of .56 $(p<.01)$. We also assessed the influence of RE after accounting for the effect of trust and collaboration, with trust and collaboration entered in the first block and $\mathrm{RE}$ entered in the second block. Results indicate that RE explained an additional 3.6 percent of the variance in RIP, above both trust and collaboration $(F$ Change $=3.2, p<.08)$.

\section{Hypotheses testing}

Table 6 shows the descriptive statistics of our variables. To test our hypotheses, we performed a series of hierarchical regression analyses, with the control variables, including trust, in the first step. We examined Hypothesis 1, which posited a positive relationship between team RE and team RIP. The results of Model 2 in Table 7 support this hypothesis $(\beta=.30, p<.01)$. 
Table 7. Study 3, hierarchical regression results for the prediction of information processing and team creativity.

\begin{tabular}{|c|c|c|c|c|}
\hline & Model I $\beta$ & Model $2 \beta$ & Model $3 \beta$ & Model $4 \beta$ \\
\hline & Team creativity & RIP & $\begin{array}{l}\text { Team } \\
\text { creativity }\end{array}$ & $\begin{array}{l}\text { Team } \\
\text { creativity }\end{array}$ \\
\hline Constant $^{(1)}$ & $4.25\left(9.04^{* *}\right)$ & $.33(.55)$ & $4.00\left(9.04^{* * *}\right)$ & $4.14\left(9.52^{* *}\right)$ \\
\hline Sector $(I=$ Service $)$ & $-.05(-.46)$ & $.01(.08)$ & $-.05(-.43)$ & $-.06(-.53)$ \\
\hline Team size & $.05(.45)$ & $.26\left(2.35^{*}\right)$ & $-.10(-.89)$ & $-.05(-.49)$ \\
\hline Team tenure & $-.16(-1.36)$ & $-.01(-.05)$ & $-.14(-1.26)$ & $-.16(-1.44)$ \\
\hline Education & $-.16(-1.42)$ & $-.15(-1.29)$ & $-.07(-.63)$ & $-.11(-.97)$ \\
\hline $\begin{array}{l}\text { Perceived environmental } \\
\text { uncertainty }\end{array}$ & $.08(.73)$ & $.12(1.01)$ & $.05(.44)$ & $.04(.35)$ \\
\hline$R^{2}$ & .049 & .083 & .049 & .049 \\
\hline Adjusted $R^{2}$ & .02 & .017 & .02 & .02 \\
\hline$F$ for $R^{2}$ & .726 & 1.266 & .726 & .726 \\
\hline SE of the estimate & .451 & .569 & .451 & .451 \\
\hline$R I P$ & & & $.47\left(4.33^{* * k}\right)$ & $.40\left(3.55^{* *}\right)$ \\
\hline$\Delta R^{2}$ & & & .203 & .203 \\
\hline$F$ for $\Delta R^{2}$ & & & $|8.7|^{* *}$ & $|8.7|^{* *}$ \\
\hline$R^{2}$ & & & .252 & .252 \\
\hline Adjusted $R^{2}$ & & & .187 & .187 \\
\hline SE of the estimate & & & .402 & .402 \\
\hline$R E$ & $.36\left(3.20^{* *}\right)$ & $.30\left(2.69^{* *}\right)$ & & $.24\left(2.20^{*}\right)$ \\
\hline$\Delta R^{2}$ & .123 & .087 & & .05 \\
\hline$F$ for $\Delta R^{2}$ & $10.246^{* *}$ & $7.208^{* *}$ & & $4.839^{*}$ \\
\hline$R^{2}$ & .172 & .170 & & .302 \\
\hline Adjusted $R^{2}$ & .10 & .10 & & .23 \\
\hline SE of the Estimate & .424 & .546 & & .392 \\
\hline
\end{tabular}

(I)Unstandardized coefficients; ${ }^{*} p<.05,{ }^{* *} p<.01 . \mathrm{SE}=$ standard error; RIP = relational information processing; RE = respectful engagement.

We also tested whether RIP was positively related to team creativity (Hypothesis 2), and whether RIP mediated the relationship between RE and team creativity (Hypothesis 3). As in Bootstrap analysis, Preacher and Hayes (2004) indicated that the indirect effect through RIP is significant $(95 \% \mathrm{CI}=.122$ [lower], .509 [upper]; $p=.02)$, supporting a mediation model.

\section{Study 4, method}

In Study 4, we examine our hypotheses in a different national context. We focused on employees at a large US Midwest university, collecting data at two points in time. This study allowed us to further test the discriminant validity and examine the predictive power of RE in comparison with other variables: cohesion, POS, psychological safety and task conflict. 


\section{Sample and procedure}

In Study 4, we surveyed 250 full-time employees at a large university, using an existing subject pool that is recruited once a year through recruitment emails sent to a random selection of employees. We used Qualtrics to collect data at two points in time, separated by two weeks. In a cover letter to the subject pool respondents, we briefly indicated the goals of the study and assured participants full confidentiality. We received 194 usable surveys (participants completed both surveys; overall response rate of $77.6 \%$ ). The respondents' average age was 24 years (SD 12) and their average tenure in the organization was three years (SD 1.8). Seventy-nine percent of the respondents were female; 51 percent pursued a college degree or held a BA degree; 27.8 percent had a MA degree; and the remaining held a PhD degree.

\section{Measures}

Responses were reported on a five-point scale $(1=$ not at all, to $5=$ to a very large extent). Measures for creative behavior ( $\alpha=.90$; Baer and Oldham, 2006), RIP $(\alpha=.73)$ and RE $(\alpha=.94)$ were consistent with measures in Study 1. We continue to control for gender differences, age, tenure in the organization and education.

\section{Study 4, results}

\section{Construct validity}

In study 4, we assess the construct validity of RE in relation to POS, cohesion, psychological safety and task conflict. We measured POS using an existing seven-item scale (e.g. organizational members care about my well-being; $\alpha=.93$; Coyle-Shapiro and Conway, 2005; Eisenberger et al., 1986). We measured cohesion using an existing three-item scale (e.g. most of the people in this organization are not the kind of people I would enjoy spending time with outside the organization; $\alpha=.75$; Stokes, 1983). To measure psychological safety, we adapted an existing scale (e.g. everyone's view is listened to, even if it is in minority; $\alpha=.95$; Anderson and West, 1994). Finally, we measured task conflict using three items from an existing scale (e.g. how frequently do you have disagreements within your organization about the tasks you are working on; $\alpha=.81$; Jehn, 1995).

Our factor analysis of these four construct and RE produced a five-factor solution, demonstrating the constructs are distinct. The first factor, RE, had an eigenvalue of 15.06 and explained 20.78 percent of the variance; the second factor, psychological safety, had an eigenvalue of 2.15 and explained 20.75 percent of the variance; the third factor, POS, had an eigenvalue of 1.57 and explained 13.61 percent of the variance; the fourth factor, cohesion, had an eigenvalue of 1.47 and explained 8.22 percent of the variance; and the fifth factor, conflict, had an eigenvalue of 1.16 and explained 8.01 percent of the variance. None of the items exhibited cross-loadings greater than .30 .

\section{Hypotheses testing}

Consistent with previous studies, to establish discriminant validity, we performed a CFA with RE, RIP and creative behaviors. We compared a three-factor model with a 
Table 8. Study 4, means, SD and correlations.

\begin{tabular}{lllllllllllll}
\hline & Mean & SD & 1 & 2 & 3 & 4 & 5 & 6 & 7 & 8 & 9 & 10 \\
\hline $\begin{array}{l}\text { Gender } \\
\text { Education }\end{array}$ & - & - & 1.00 & & & & & & & & \\
Organizational & 5.19 & .95 & -.11 & 1.00 & & & & & & & \\
tenure & 3.28 & 1.79 & .11 & -.11 & 1.00 & & & & & & \\
POS & & & & & & & & & & & \\
Cohesion & 3.40 & .80 & -.04 & .12 & -.09 & 1.00 & & & & & \\
Psychological safety & 2.83 & .90 & .06 & .06 & -.04 & $.43^{* *}$ & 1.00 & & & & \\
Conflicts & 3.32 & .87 & -.11 & .10 & .01 & $.69^{* *}$ & $.34^{* *}$ & 1.00 & & & & \\
RE & 2.75 & .71 & .06 & .05 & .05 & $-.46^{* *}$ & $-.25^{* *}$ & $-.46^{* *}$ & 1.00 & & & \\
RIP & 3.25 & .80 & -.01 & .13 & -.13 & $.79^{* *}$ & $.44^{* *}$ & $.73^{* *}$ & $-.53^{* *}$ & 1.00 & & \\
Creative behaviors & 3.24 & .81 & -.13 & $.18^{*}$ & -.09 & $.15^{*}$ & .11 & .10 & -.01 & $.18^{*}$ & $.54^{* *}$ & 1.00 \\
\hline
\end{tabular}

$N=194$ Two-tailed test. SD - standard deviation; POS = perceived organizational support; RIP = relational information processing; RE = respectful engagement.

${ }^{*} p<.05,{ }^{* *} p<.01$.

two-factor model (collapsing RE and RIP) and a one-factor model (collapsing all three constructs). Results indicated that a three-factor model showed an acceptable fit with the data $\left(\chi^{2}\right.$ [d.f.] $=281.2[116]$ IFI $=.937$, TLI $=.916$, CFI $=.936$ and RMSEA $=.078)$, compared to either a two-factor model $\left(\chi^{2}[\mathrm{~d} . \mathrm{f}]=.563.6[118]\right.$, IFI $=.831$, TLI $=.777, \mathrm{CFI}=.828$ and $\mathrm{RMSEA}=.126)$, or a one-factor model $\left(\chi^{2}\right.$ [d.f.] $=1224.1$ $[119]$, IFI $=.567, \mathrm{TLI}=.443, \mathrm{CFI}=.567$ and $\mathrm{RMSEA}=.20)$, thus establishing the discriminant validity of the research variables.

Table 8 shows the descriptive statistics of our variables. Using Hayes (2012) PROCESS in SPSS, we tested the mediation model, including POS, cohesion, task conflict, psychological safety, age, tenure and education as control variables. The link between RE and $\mathrm{RIP}$ is significant (coefficient $=.24, p<.01$; bootstrap CI does not include zero [CI $(95 \%)$ $=(.08, .40)])$. The link between RIP and creative behavior is significant (regression coefficient $=.25, p<.01$; bootstrap CI does not include zero $[\mathrm{CI}(95 \%)=(.13, .36)])$. The total effect of RE on creative behavior was not significant $(.02, p>.10$; CI [95\%] $=-.22, .25)$. Normal theory test for indirect effect is significant $(.06, p<.05 ; \mathrm{SE}=.02, \mathrm{Z}=2.40$; CI $[95 \%]=.02, .12)$. This lends support to our hypothesized mediation model.

\section{Discussion}

Organizations are fertile terrains for interrelating that can either build or destroy human accomplishments, including creativity. This article unravels the ways RE, a particularly generative form of interrelating, can facilitate creativity. Our studies show that the connection between RE and creativity holds at both the individual and team levels, suggesting that this mode of positive interrelating may have a uniform link to creativity.

Our research contributes to understanding the relational underpinnings of creativity in organizations. While previous research has focused on network structure (Uzzi and Spiro, 2005), strength of ties (Baer, 2010; Perry-Smith, 2006) or social exchange (Liao et al., 2010), our studies capture how ways of interrelating facilitate a sense of 
awareness, acceptance and mutuality that impacts creativity through increasing RIP. This perspective on relationships at work enriches our understanding of how patterns of interrelating build individuals' capacities (and the space between them [Josselson, 1995]), making them more creative. We highlight the possibility of new resource creation and capability enhancement through the ways that people interact. Thus, rather than seeing creativity as the result of the exchange of resources (network studies) or the provision of resources from others (e.g. through social or coworker support), the engine for creativity is coming from the quality of connections cultivated by the way that people interact and how they process work-related information reflectively together in conversation.

Our findings expand previous work on respect. Research in various fields points to the importance of respect as a basic condition for human economic welfare (e.g. Sennett, 2003) and healthy educational systems (Poplin and Weeres, 1994). We provide new insights, capturing the importance of RE, as well as its connection to core cognitive processes, such as creativity, for theories of positive work relationships and creative behaviors.

For theories of relationships in organizations, our findings suggest that RE adds value by cultivating a way of being that is marked by increasing awareness and acceptance of others, motivating attention and interest, and fostering mutuality. Thus, our studies expand understanding of relationships conducive to creativity and further develop theories of how positive relationships at work matter more broadly (Dutton and Ragins, 2007). While future research should test the micro-mechanisms activated by RE, we theorize how concrete behaviors (such as greater listening, conveying genuine interest, emphasizing strengths and making requests not demands) translate into more RIP. We explore how RE is conducive to RIP, which in turn is associated with higher levels of creative behavior. Across our studies, we demonstrate that RE is more than simply a nice way to interact, but is a catalyst and cultivator of RIP and creativity.

Our research also contributes to the literature by unpacking how RE, a unique means of capturing patterns of interrelating, has implications at both the individual and team level. We highlight this unique and critical aspect of interpersonal relating at work, which should be considered as a distinct relational construct. Current research points to the importance of this basic form of human-to-human interaction in work organizations (Stephens et al., 2012), which lends support to our theorizing about the potency of RE. Research on RE can be further advanced by unraveling the unique potential of this construct in developing emotional, behavioral and cognitive capacities.

Our studies also shed light on how the process of reflection-in-conversation can be an important enabler of creativity. Research on information processing offers useful insight on why this process is beneficial for improving decision-making, learning and performance (e.g. De Dreu et al., 2008; Di Stefano et al., 2014). Our work extends this research by highlighting reflection-in-conversation as a key process in which people are exposed to additional ideas, are more attentive to others' ideas, are more willing to combine ideas and develop enriched awareness of the surroundings. Our focus on RIP, as compared with selfreflection, opens up opportunities to develop theory about how this mechanism may build core capabilities key for continuous work improvement, such as knowledge creation, coordinating and capacity to manage conflicting demands. For example, organizations such as Pixar have enacted RIP and were able to develop high quality, creative products over a long period of time. However, we need further research to better understand how RIP uniquely contributes to building new capabilities in organizations. 


\section{Limitations and future directions}

Our research is not without limitations despite the inclusion of studies that involve participants located in two countries, with varying levels of employment. Future research must investigate whether our results are replicable and extend to other settings. Additionally, inferences about causality are not conclusive based on evidence of covariation alone. The cross-sectional nature of Studies 2 and 3 limit the empirical tests for mediating mechanisms. We attempted to mitigate this issue with time-lagged data in Studies 3 and 4, however, conducting cross-lagged research using an experimental design would be ideal to test for causation.

Across all studies, we tried to show that RE is a unique form of interrelating. However, we acknowledge that we have not simultaneously included all potential constructs that may explain variation in RIP and creative behaviors. Future research should explore unobserved variables to eliminate alternative explanations that may account for the links between RE, RIP and creativity, and more directly assess the effects of RE. For example, engaging respectfully is a relational mechanism that could drive creativity by augmenting identification processes on the one hand and persistence and resiliency on the other. This is important given recent work that points to a dual pathway for creativity (De Dreu et al., 2008). We hope future work will consider the expanding the context, exploring conditions where RE may be more critical for creativity. Further studies may explore additional outcomes such as positive emotions, satisfaction and pro-social behaviors.

Across a set of four samples, in line with our theoretical expectations, we found that RE has positive correlations with psychological safety, LMX, trust, collaboration, POS, cohesion, but remains distinct from these constructs and thus provides evidence of 'discriminant validity' (Campbell and Fiske, 1959). Further, collinearity tests should indicate that a tolerance of more than .20 and a variance inflation factor (VIF) of less than 10. In Study 4, we observed a high correlation between RE and POS; however the tolerance and VIF levels indicated no problem of multicollinearity (Belsley et al., 1980). Nevertheless, we acknowledge the need for further tests to establish discriminant validity.

We also acknowledge the limitations in the use of a subjective assessment of creativity; however, past work has explored why this may be appropriate (Conway and Lance, 2010; Hocevar, 1981). Creativity is often a process involving self-awareness, is intentional in nature and is accompanied by subjective experiences and thus, 'understanding individuals' self-perceptions and subjective experiences of their creativity is the first step toward understanding the entire process of creativity' (Zhou et al., 2008: 399-400). In addition, it may be that creative behaviors are not observed by others, creating misalignment in the way individuals perceive their creativity and the ways others perceive their behavior (Zhou et al., 2008). Employees are aware of the subtlety of their work and thus are more equipped to assess their level of creativity (Shalley et al., 2009). Despite this, research does indicate a positive correlation between self and supervisor-ratings of creativity $(r=.62)$ (Shalley et al., 2009). There are clearly different approaches to assess creativity. Nevertheless, in both Study 1 and Study 2, we tried to mitigate potential biases by asking the employees not to report on their perceptions of creative behaviors, but rather tapped construed external creativity by asking respondents to assess how they believed their managers evaluated their level of creative behavior. 


\section{Conclusion}

Since individuals spend the majority of their time from the age of 20 to 70 in organizations and relationships are central to the meaning of being, relationships in the workplace are of paramount importance (Dutton and Ragins, 2007; Gini, 1998). They are the seed-corn for important human accomplishments such as creativity. This series of studies has expanded the repertoire of theoretical lenses for examining how relationships at work matter for creativity, beyond networks of social exchange, by defining and testing how two core concepts - RE and RIP - open up new levels of understanding about the relational roots of new ideas in work organizations. It is our hope that this initial set of studies will encourage and inspire deeper inquiry into how the everyday enactment of respect at work increases possibilities for new ideas through shaping the manner in which information is processed. In a more demanding work world the cultivation of respect is challenging, these studies remind us of the potential yield from making RE an interpersonal goal and a strategic imperative.

\section{Acknowledgements}

We would like to thank Associate Editor Professor Mathew Sheep and anonymous reviewers for their constructive and helpful feedback, as well as Lindsay Chmielewski and Esther Singer for their editorial comments. All remaining errors are ours.

\section{Funding}

The first author acknowledges the financial support of the Henry Crown Institute of Business Research in Israel (grant number 2013) and the Hurvitz Institute of Strategic Management, both at the Faculty of Management, Tel Aviv University, Israel.

\section{Notes}

1 The key explanatory variables were not used in previous studies (RE and RIP); however, creative behavior was used to test a different model in another study (Carmeli and Paulus, forthcoming).

2 The practice of using a team leader (in our case the firm's CEO) to assess team creativity is widely used in organizational science. To address the issue of reliance on self-report measures, we followed previous research (Carmeli and Schaubroeck, 2007) and performed CFA to test a congeneric measurement model that shows that the hypothesized three-factor model fits the data better than both a two- and one-factor solutions, suggesting potential biases are likely not severe.

\section{References}

Amabile TM (1983) The Social Psychology of Creativity. New York: Springer-Verlag.

Amabile TM (1988) A model of creativity and innovation in organizations. In: Staw BM and Cummings LL (eds) Research in Organizational Behavior. Greenwich, CT: JAI Press, pp. 123-167.

Anderson N and West M (1994) The personality of teamworking. Personnel Management 26(11): 81-83.

Ashforth BE and Kreiner GE (1999) 'How can you do it?': Dirty work and the challenge of constructing a positive identity. Academy of Management Review 24(3): 413-434.

Baer M (2010) The strength-of-weak-ties perspective on creativity: A comprehensive examination and extension. Journal of Applied Psychology 95(3): 592-601.

Baer M and Oldham GR (2006) The curvilinear relation between experienced creative time pressure and creativity: Moderating effects of openness to experience and support for creativity. Journal of Applied Psychology 91(4): 963-970. 
Baumeister R and Leary MR (1995) The need to belong: Desire for interpersonal attachments as a fundamental human motivation. Psychological Bulletin 117(3): 497-529.

Belsley DA, Kuh E and Welsch RE (1980) Regression Diagnostics: Identifying Influential Data and Sources of Collinearity. New York: Wiley.

Bishop SR, Lau M, Shapiro S et al. (2004) Mindfulness: A proposed operational definition. Clinical Psychology: Science and Practice 11(3): 230-241.

Blau P (1964) Exchange and Power in Social Life. New York: Wiley.

Blader SL and Tyler TR (2009) Testing and extending the group engagement model: Linkages between social identity, procedural justice, economic outcomes, and extrarole behavior. Journal of Applied Psychology 94(2): 445-464.

Bliese PD (2000) Within-group agreement, non-independence, and reliability: Implications for data aggregation and analyses. In: Klein KJ and Kozlowski SWJ (eds) Multilevel Theory, Research, and Methods in Organizations: Foundations, Extensions, and New Directions. San Francisco, CA: Jossey-Bass, 349-381.

Burt RS (2004) Structural holes and good ideas. American Journal of Sociology 110(2): 349-399.

Campbell DT and Fiske DW (1959) Convergent and discriminant validation by the multitraitmultimethod matrix. Psychological Bulletin 56(2): 81-105.

Campbell JD, Trapnell PD et al. (1996) Self-concept clarity: Measurement, personality correlates, and cultural boundaries. Journal of Personality and Social Psychology 70(1): 141-156.

Carmeli A and Gittell JH (2009) High quality relationships, psychological safety and learning from failures in work organizations. Journal of Organizational Behavior 30: 709-729.

Carmeli A and Paulus PB (forthcoming) CEO ideational facilitation leadership and team exploratory behaviors: The mediating role of knowledge sharing. The Journal of Creative Behavior.

Carmeli A and Schaubroeck J (2007) The influence of leaders' and other referents' normative expectations on individual involvement in creative work. Leadership Quarterly 18(1): 35-48.

Carmeli A, Schaubroeck J and Tishler A (2011) How CEO empowering leadership shapes top management team processes: Implications for firm performance. The Leadership Quarterly 22(2): 399-411.

Carmeli A, Tishler A and Edmondson AC (2012) CEO relational leadership and strategic decision quality in top management teams: The role of team trust and learning from failure. Strategic Organization 10(1): 31-54.

Chiaburu DS and Harrison DA (2008) Do peers make the place? Conceptual synthesis and metaanalysis of co-worker effects on perceptions, attitudes, OCBs and performance. Journal of Applied Psychology 93(5): 1082-1103.

Chaiken S and Trope Y (eds) (1999) Dual-Process Theories in Social Psychology. New York: Guilford Press.

Conway JM and Lance CE (2010) What reviewers should expect from authors regarding common method bias in organizational research. Journal of Business and Psychology 25(3): 325-334.

Coyle-Shapiro J and Conway N (2005) Exchange relationships: Examining psychological contracts and perceived organizational support. Journal of Applied Psychology 90(4): 774-781.

De Dreu CKW (2007) Cooperative outcome interdependence, task reflexivity and team effectiveness: A motivated information processing approach. Journal of Applied Psychology 92(3): 628-638.

De Dreu CKW, Baas M and Nijstad BA (2008) Hedonic tone and activation level in the moodcreativity link: Toward a dual pathway to creativity model. Journal of Personality and Social Psychology 94(5): 739-756.

De Dreu CKW, Nijstad BA and Van Knippenberg D (2008) Motivated information processing in group judgment and decision making. Personality and Social Psychology Review 12(1): 22-49.

DeVellis RF (2003) Scale Development: Theory and Applications. Thousand Oaks, CA: SAGE.

Di Stefano G, Gino F, Pisano G and Staats B (2014) Learning by thinking: How reflection aids performance. Working paper, Harvard Business School, Boston, MA.

Dutton JE (2003) Energize Your Workplace: How to Build and Sustain High-Quality Connections at Work. San Francisco, CA: Jossey-Bass. 
Dutton JE, Debebe G and Wrzesniewski A (forthcoming) Being valued and devalued at work: A social valuing perspective. Qualitative Organizational Research: Best Papers from the Davis Conference on Qualitative Research, Volume 3, Information Age Publishing.

Dutton JE and Ragins BR (2007) Moving forward: Positive relationships at work as a research frontier. In: Dutton JE and Ragins BR (eds) Exploring Positive Relationships at Work: Building a Theoretical and Research Foundation. Mahwah, NJ: Lawrence Erlbaum Associates, 387-400.

Edmondson AC (1999) Psychological safety and learning behavior in work teams. Administrative Science Quarterly 44(2): 350-383.

Eisenberger R, Huntington R, Hutchison S and Sowa D (1986) Perceived organizational support. Journal of Applied Psychology 71(3): 500-507.

Festinger L (1950) Informal social communication. Psychological Review 57(5): 271-282.

Ford JD and Ford LW (1995) The role of conversations in producing intentional change in organizations. The Academy of Management Review 20(3): 541-570.

Fredrickson BL (1998) What good are positive emotions? Review of General Psychology 2(3): 300-319.

Fredrickson BL (2013) Love 2.0: How Our Supreme Emotion Affects Everything We Feel, Think, Do, and Become. New York: Hudson Street Press.

Friedkin NE (2004) Social cohesion. Annual Review of Sociology 30: 409-425.

Gini A (1998) Work, identity and self: How we are formed by the work we do. Journal of Business Ethics 17(7): 707-714.

Gittell JH (2003) A theory of relational coordination. In: Cameron KS, Dutton JE and Quinn RE (eds) Positive Organizational Scholarship: Foundations of a New Discipline. San Francisco, CA: Berrett-Koehler Publishers, 279-295.

Goffman E (1967) Interaction Ritual: Essays on Face-to-Face Behavior. New York: Doubleday Anchor.

Gottman JM (1994) Why Marriages Succeed or Fail... and How You Can Make Yours Last. New York: Simon \& Schuster.

Graen GB and Uhl-Bien M (1995) Relationship-based approach to leadership: Development of leader-member exchange (LMX) theory of leadership over 25 years: Applying a multi-level multi-domain perspective. Leadership Quarterly 6(2): 219-247.

Granovetter MS (1973) The strength of weak ties. American Journal of Sociology 78(6): 1360-1380.

Grant AM, Langer EJ, Falk E and Capodilupo C (2004) Mindful creativity: Drawing to draw distinctions. Creativity Research Journal 16(2-3): 261-265.

Guilford JP (1967) Creativity: Yesterday, today and tomorrow. The Journal of Creative Behavior 1(1): 3-14.

Hambrick DC (1994) Top management groups: A conceptual integration and reconsideration of the ‘team' label. In: Staw BM and Cummings LL (eds) Research in Organizational Behavior. Greenwich, CT: JAI Press, 171-214.

Hargadon A (2008) Creativity that works. In: Zhou J and Shalley CE (eds) Handbook of Organizational Creativity. New York: Lawrence Erlbaum Associates, 323-343.

Harrington DM (1990) The ecology of human creativity: A psychological perspective. In: Runco MA and Albert RS (eds) Theories of Creativity. Newbury Park, CA: SAGE, 143-169.

Hayes AF (2012) PROCESS: A versatile computational tool for observed variable mediation, moderation, and conditional process modeling [White paper]. URL: http://www.afhayes. com/public/process2012.pdf

Hocevar D (1981) Measurement of creativity: Review and critique. Journal of Personality Assessment 45(5): 450-464.

Homans GC (1974) Social Behaviour: Its Elementary Forms, revised edn. New York: Harcourt Brace Jovanovich, Inc.

Honneth A (1992) Integrity and disrespect: Principles of a conception of morality based on the theory of recognition. Political Theory 20(2): 187-201. 
Jehn KA (1995) A multi-method examination of the benefits and detriments of intragroup conflict. Administrative Science Quarterly 40(2): 256-282.

Josselson R (1995) The Space Between Us: Exploring the Dimensions of Human Relationships. Newbury Park, CA: SAGE.

Kahn WA (1992) To be fully there: Psychological presence at work. Human Relations 45(4): 321-349.

Khazanchi S and Masterson SS (2011) Who and what is fair matters: A multi-foci social exchange model of creativity. Journal of Organizational Behavior 32(1): 86-106.

Kohn NW, Paulus PB and Choi Y (2011) Building on the ideas of others: An examination of the idea combination process. Journal of Experimental Social Psychology 47(3): $554-561$.

Langer EJ and Moldoveanu M (2000) The construct of mindfulness. Journal of Social Issues 56(1): $1-9$.

Lewis K and Herndon B (2011) Transactive memory systems: Current issues and future research directions. Organization Science 22(5): 1254-1265.

Liao H, Liu D and Loi R (2010) Looking at both sides of the social exchange coin: A social cognitive perspective on the joint effects of relationship quality and differentiation on creativity. Academy of Management Journal 53(5): 1090-1109.

Liden RC and Maslyn JM (1998) Multidimensionality of leader-member exchange: An empirical assessment through scale development. Journal of Management 24(1): 43-72.

Lubatkin MH, Simsek Z, Ling Y and Veiga JF (2006) Ambidexterity and performance in small- to medium-sized firms: The pivotal role of TMT behavioral integration. Journal of Management 32(5): 646-672.

Mayer RC, Davis JH and Schoorman FD (1995) An integrative model of organizational trust. Academy of Management Review 20(3): 709-734.

Mead GH (1934) Mind, Self, and Society. Chicago, IL: University of Chicago Press.

Miller D and Droge C (1986) Psychological and traditional determinants of structure. Administrative Science Quarterly 31(4): 539-560.

Miller JB and Stiver IP (1997) The Healing Connection. Boston, MA: Beacon Press.

Mueller JS and Kamdar D (2011) Why seeking help from teammates is a blessing and a curse: A theory of help seeking and individual creativity in team contexts. Journal of Applied Psychology 96(2): 263-276.

Nijstad BA and Paulus PB (2003) Group creativity: Common themes and future directions. In: Paulus PB and Nijstad BA (eds) Group Creativity: Innovation through Collaboration. New York: Oxford University Press, 326-339.

Nonaka I (1994) A dynamic theory of organizational knowledge creation. Organization Science 5(1): 14-37.

O'Reilly CA and Flatt S (1989) Executive team demography: Organizational innovation and firm performance. Working paper, University of California, Berkeley.

Paulus PB (2000) Groups, teams and creativity: The creative potential of idea-generating groups. Applied Psychology: An International Review 49(2): 237-262.

Paulus PB (2008) Fostering creativity in groups and teams. In: Zhou J and Shalley CE (eds) Handbook of Organizational Creativity. New York: Lawrence Erlbaum Associates, 165188.

Paulus PB and Coskun H (2012) Group creativity. In: Levine JM (eds) Group Processes. London: Psychology Press, 215-239.

Perry-Smith JE (2006) Social yet creative: The role of social relationships in facilitating individual creativity. Academy of Management Journal 49(1): 85-101.

Perry-Smith JE and Shalley CE (2003) The social side of creativity: A static and dynamic social network perspective. Academy of Management Review 28(1): 89-106.

Podsakoff PM, MacKenzie SB and Podsakoff NP (2012) Sources of method bias in social science research and recommendations on how to control it. Annual Review of Psychology 63: 539-569. 
Poplin M and Weeres J (1994) Voices from the Inside: A Report on Schooling from Inside the Classroom. Claremont, CA: Institute for Education in Transformation at the Claremont Graduate School.

Preacher KJ and Hayes AF (2004) SPSS and SAS procedures for estimating indirect effects in simple mediation models. Behavior Research Methods, Instruments, \& Computers 36(4): 717-731.

Rafferty AE and Griffin MA (2004) Dimensions of transformational leadership: Conceptual and empirical extensions. Leadership Quarterly 15(3): 329-354.

Ramarajan L, Barsade SG and Burack O (2008) The influence of organizational respect on emotional exhaustion in the human services. Journal of Positive Psychology 3(1): 4-18.

Rawls J (1971) A Theory of Justice. Cambridge, MA: Harvard University Press.

Rhoades L and Eisenberger R (2002) Perceived organizational support: A review of the literature. Journal of Applied Psychology 87(4): 698-714.

Rietzschel EF, De Dreu CKW and Nijstad BA (2009) What are we talking about when we talk about creativity: Group creativity as a multifaceted multistage phenomenon. In: Mannix EA, Neale M and Goncalo JA (eds) Research on Managing Groups and Teams: Creativity in Groups. Palo Alto, CA: Jossey-Bass, 1-23.

Robinson S (1996) Trust and breach of the psychological contract. Administrative Science Quarterly 41(4): 574-599.

Rochlin GI (1989) Informal organizational networking as a crisis-avoidance strategy: US naval flight operations as a case study. Organization \& Environment 3(2): 159-176.

Rogers CR (1957) The necessary and sufficient conditions of therapeutic personality change. Journal of Consulting Psychology 21(2): 95-103.

Rogers CR (1967) The interpersonal relationship: The core of guidance. In: Rogers CR and Stevens B (eds) Person to Person: The Problem of Being Human. New York: Pocket Books, 85-101.

Rosenberg MB (2003) Nonviolent Communication: A Language of Life, 2nd edn. Encinitas, CA: Puddle Dancer.

Salanick GS and Pfeffer J (1978) A social information processing approach to job attitudes and task design. Administrative Science Quarterly 23(2): 224-253.

Sennett R (2003) Respect in a World of Inequality. New York: W.W. Norton \& Co.

Shalley CE, Gilson LL and Blum TC (2009) Interactive effects of growth need strength, work context, and job complexity on self-reported creative performance. Academy of Management Journal 52(3): 489-505.

Shin SJ and Zhou J (2007) When is educational specialization heterogeneity related to creativity in research and development teams? Transformational leadership as a moderator. Journal of Applied Psychology 92(6): 1709-1721.

Simonton DK (2000) Creativity: Cognitive, developmental, personal, and social aspects. American Psychologist 55(1): 151-158.

Sosa ME (2011) Where do creative interactions come from? The role of tie content and social networks. Organization Science 22(1): 1-21.

Stephens JP, Heaphy E and Dutton JE (2012) High-quality connections. In: Cameron K and Spreitzer G (eds) The Oxford Handbook of Positive Organizational Scholarship. New York: Oxford University Press, 385-400.

Stephens JP, Heaphy ED, Carmeli A, Spreitzer GM and Dutton JE (2013) Relationship quality and virtuousness: Emotional carrying capacity as a source of individual and team resilience. The Journal of Applied Behavioral Science 49(1): 13-41.

Sternberg RJ and Lubart TI (1996) Investing in creativity. American psychologist 51(7): 677-688.

Stokes JP (1983) Components of group cohesion: Intermember attraction, instrumental value, and risk taking. Small Group Behavior 14(2): 163-173.

Storm C and Storm T (1987) A taxonomic study of the vocabulary of emotions. Journal of Personality and Social Psychology 53(4): 805-816. 
Tepper BJ (2007) Abusive supervision in work organizations: Review, synthesis, and research agenda. Journal of Management 33(3): 261-289.

Thibaut JW and Kelley HH (1959) The Social Psychology of Groups. New York: Wiley.

Tjosvold D, Johnson DW and Lerner J (1981) Effects of affirmation and acceptance on incorporation of opposing information in problem-solving. The Journal of Social Psychology 114(1): $103-110$.

Uzzi B and Spiro J (2005) Collaboration and creativity: The small world problem. American Journal of Sociology 111(2): 447-504.

Van Kleef GA, De Dreu CKW and Manstead ASR (2004) The interpersonal effects of emotions in negotiation: A motivated information processing approach. Journal of Personality and Social Psychology 87(4): 510-528.

Vogus TJ (2006) What is it about relationships? A behavioral theory of social capital and performance. In: Eaton A (ed.) Labor and Employment Relations Association Series. Boston, MA: Labor and Employment Relations Association, 164-173.

Vogus TJ (2011) Mindful organizing: Establishing and extending the foundations of highly reliable performance. In: Cameron K and Spreitzer GM (eds) The Oxford Handbook of Positive Organizational Scholarship. Oxford: Oxford University Press, 664-676.

Weick KE (1993) The collapse of sensemaking in organizations: The Mann Gulch disaster. Administrative Science Quarterly 38(4): 628-652.

West MA (1996) Reflexivity and work group effectiveness: A conceptual integration. In: West MA (eds) Handbook of Work Group Psychology. Chichester: Wiley, 555-579.

Williams LJ and Anderson SE (1994) An alternative approach to method effects by using latentvariable models: Applications in organizational behavior research. Journal of Applied Psychology 79(3): 323-331.

Zhou J and George JM (2001) When job dissatisfaction leads to creativity: Encouraging the expression of voice. Academy of Management Journal 44(4): 682-696.

Zhou J, Shin SJ and Cannella AA Jr (2008) Employee self-perceived creativity after mergers and acquisitions: Interactive effects of threat-opportunity perception, access to resources, and support for creativity. Journal of Applied Behavioral Sciences 44(4): 397-421.

\begin{abstract}
Abraham Carmeli is a professor of strategy and management at Tel Aviv University, Faculty of Management-Recanati Graduate School of Business, Israel. He received his $\mathrm{PhD}$ from the University of Haifa. His current research interests include leadership and top management teams, relational dynamics, learning from failures, and creativity and innovation in the workplace. [Email: avic@post.tau.ac.il]
\end{abstract}

Jane E Dutton is the Robert L Kahn Distinguished University Professor of Business Administration and Psychology at the University of Michigan, USA. She is Co-Founder of the Center for Positive Organizations at the Ross School of Business. Her research focuses on positive relationships at work, compassion, positive identities and job crafting. She has published or co-edited 13 books and published over 100 articles or book chapters. Her most recent book (with Gretchen Spreitzer) is How to Be a Positive Leader: Small Actions, Big Impact (Berrett-Koehler, 2014). She has been awarded the Distinguished Scholar Award for the Organization and Management Theory Division, the Organization Development and Change Division, and the Managerial and Organizational Cognition Division of the Academy of Management, and in 2012 she was awarded the Scholarly Contributions Award for the Academy of Management. [Email: janedut@umich.edu]

Ashley E Hardin is a PhD Candidate at the University of Michigan, Stephen M Ross School of Business in the management and organizations department. Her research focuses on positive interrelating in organizations, including compassion at work, respectful engagement and ethical behavior. She is particularly interested in examining how existing organizations can create an environment with higher compassion capability. [Email: aehardin@umich.edu] 